\title{
ESTIMATION OF SHIE GLACIER SURFACE MOVEMENT USING OFFSET TRACKING TECHNIQUE WITH COSMO-SKYMED IMAGES
}

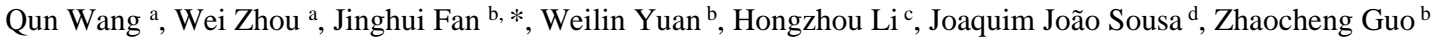 \\ a School of Land Science and Technology, China University of Geosciences, Beijing 100083, China \\ ${ }^{\mathrm{b}}$ China Aero Geophysical Survey and Remote Sensing Centre for Land and Resources, Beijing 100083, China \\ ${ }^{\mathrm{c}}$ Satellite Surveying and Mapping Application Center, NASG, Beijing 100048, China, \\ ${ }^{\mathrm{d}}$ University of Trás-os-Montes e Alto Douro, Vila Real, and INESC TEC (formerly INESC Porto), Portugal \\ jhfan2004@qq.com
}

KEY WORDS: Synthetic Aperture Radar, Shie glacier, Offset tracking technique, Glacier surface movement, COSMO-SkyMed

\begin{abstract}
:
Movement is one of the most important characteristics of glaciers which can cause serious natural disasters. For this reason, monitoring this massive blocks is a crucial task. Synthetic Aperture Radar (SAR) can operate all day in any weather conditions and the images acquired by SAR contain intensity and phase information, which are irreplaceable advantages in monitoring the surface movement of glaciers. Moreover, a variety of techniques like DInSAR and offset tracking, based on the information of SAR images, could be applied to measure the movement. Sangwang lake, a glacial lake in the Himalayas, has great potentially danger of outburst. Shie glacier is situated at the upstream of the Sangwang lake. Hence, it is significant to monitor Shie glacier surface movement to assess the risk of outburst. In this paper, 6 high resolution COSMO-SkyMed images spanning from August to December, 2016 are applied with offset tracking technique to estimate the surface movement of Shie glacier. The maximum velocity of Shie glacier surface movement is $51 \mathrm{~cm} / \mathrm{d}$, which was observed at the end of glacier tongue, and the velocity is correlated with the change of elevation. Moreover, the glacier surface movement in summer is faster than in winter and the velocity decreases as the local temperature decreases. Based on the above conclusions, the glacier may break off at the end of tongue in the near future. The movement results extracted in this paper also illustrate the advantages of high resolution SAR images in monitoring the surface movement of small glaciers.
\end{abstract}

\section{INTRODUCTION}

Glaciers are the recorder and natural indicator of climate change (Strozzi et al., 2008). As an important component of glaciers, mountain glaciers are more sensitive to global climate variations (Kääb, 2005a), which are recognized as one of the top priority climate indicators (McCarthy et al., 2001). The glacial lake outburst, which is associated with mountain glaciers, often leads to floods and debris flow, is threatening property and lives of local people (Liu et al., 2016). Therefore, monitoring the status of mountain glaciers is an important basis for assessing the risks of glaciers and glacial lakes.

Mountain glaciers are mostly located in high-altitude areas with adverse circumstances, therefore, it is hard to carry out regular and extensive field survey which usually results in a waste of time and energy (Kääb, 2005b). With the development of satellite remote sensors, especially synthetic aperture radar satellite, large spatial-coverage and high spatial-resolution monitoring the status of glaciers have become a reality (Wang et al., 2016). Field survey has mostly become a validating process of RS results. On the other hand, the cloudy, rainy, and snowy weather conditions are strong limitations that affect the use of optical remote sensing in mountain glacier areas which further highlight the advantages of SAR-based methodologies (Fallourd et al., 2011). For instance, there exist several SAR interferometric methodologies that use the amplitude or the phase of the SAR image that can be used to measure glacier surface movement, such as Differential SAR Interferometry (DInSAR), multiple aperture interferometric (MAI) and offset tracking technique.

Previous studies already showed the strengths of SAR. Based on the phase information of ERS-1 SAR image and DInSAR technique, Goldstein et al. successfully estimated the displacement of the Antarctic glacier in the horizontal and vertical directions (Goldstein et al., 1993), which is significant in the history of monitoring glacier movement. The DInSAR technique, however, relies on coherence between two images and has little sensibility to displacement in azimuth direction which limits its application range. In this context, the offset tracking technique, which can estimate glacier offset directly in both slant-range and azimuth directions whether the coherence retained or not, has been becoming an alternative method to DInSAR for measuring glacier movement although the precision of the results would be lower than DInSAR (Strozzi et al., 2002). Based the offset tracking technique, Zhou Chunxia extracted the glacier offset fields in the Grove mountain area using ENVISAT ASAR data and confirmed the reliability of the results by comparing with GPS measurements and ice velocity MEaSUREs (Zhou et al., 2015). The accuracy of offset tracking results is related to the co-registration errors, according to different co-registration algorithms, which may reach $1 / 20$ to $1 / 30$ of pixel size (Casu et al., 2011). For example, errors may be one meter when using ERS or ENVISAT data (Riveros el al., 2013). But with the launch of ALOS-2, TerraSAR-X, COSMO-

* Corresponding author 
SkyMed and Radarsat-2 satellites in recent years, the data with high resolution, multi-polarization modes and different bands have been available. Then estimation errors may be less than 10 $\mathrm{cm}$ when using these SAR images. A variety of SAR images offer more choices and possibilities to monitor glacier surface movement and morphological changes, especially in monitoring small glaciers.

In this paper, by applying offset tracking technique to COSMOSkyMed images, we were able to estimate the high-resolution and high-precision surface velocity distribution maps of Shie glacier in Kangma County, Tibet during different periods, which demonstrates the advantages of high resolution SAR images in monitoring small glaciers. And according to the extracted glacier movement fields, we analyzed its flow characteristics.

\section{STUDY AREA AND DATASETS}

Sangwang Lake is the second largest glacial lake in the Himalayas with the area $5.7 \mathrm{~km}^{2}$. In 1954, outburst of Sangwang Lake dams caused grave losses of life and property of the lower reaches. According to the investigation, the end of glacier tongue collapsed and slid into Sangwang Lake that day, eventually resulted in a great flood in history (Ran et al., 2014). Liu Chunling et al. think whether glacial lakes are dangerous depends on steep slopes, broken rock around the glacial lakes, glaciers in the upstream of lakes, enough water storage and hazard object in the downstream. Based on the above description, they believe Sangwang Lake has a significant risk of disaster (Liu et al., 2016). Shie glacier is located in upstream of Sangwang Lake, which is closely related to the security of the glacial lake. Hence, to study this glacier can help to assess the risk of Sang Wang Lake. Shie glacier is in the north and south trend, about $3 \mathrm{~km}$ long and its glacier tongue is about $0.8 \mathrm{~km}$ wide. Compared with most of valley glaciers, Shie glacier has the smaller area. So it is difficult to obtain accurate glacier surface movement when using low-resolution SAR images.

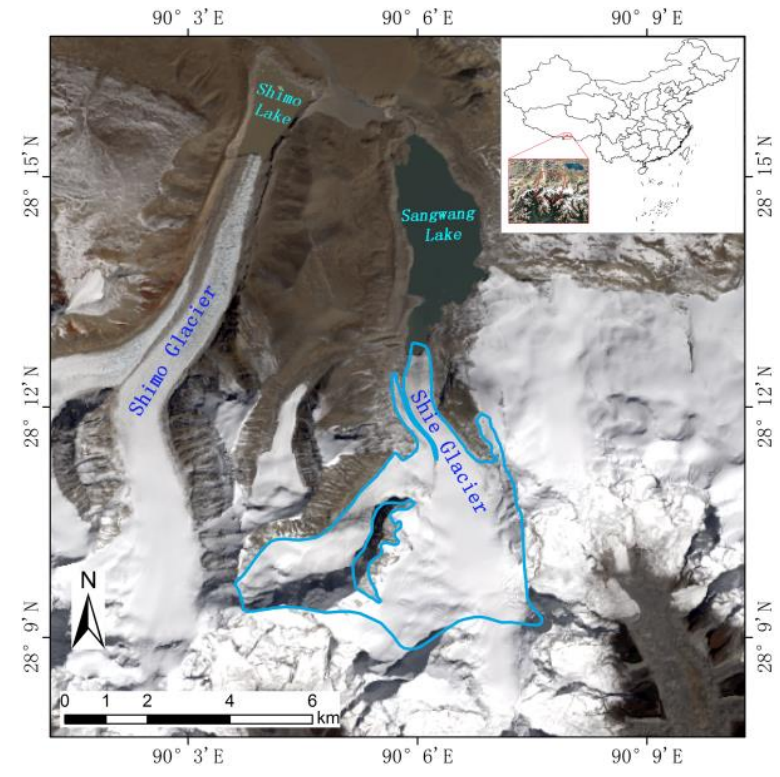

Figure 1. Landsat-8 image of the study area and the extent of Shie glacier in the second glacier inventory of China.
The COSMO-SkyMed system is a high-resolution radar satellites constellation consisting of four X-band synthetic aperture radar sensors for earth observation and developed by the Italian Space Agency and the Italian MoD (Italian Space Agency, 2016). With large spatial-coverage, high spatialresolution and low revisit-period, COSMO-SkyMed images have great advantages when used to monitor glacier change.

Six COSMO-SkyMed images, spanning from August to December, 2016 and covering the region Sangwang Lake and Shie glacier, are collected to extract the glacier movement in this study (table 1). SRTM DEM data with resolution of about $30 \mathrm{~m}$ are employed to remove topographic effects (USGS Earth Resource Observation and Science (EROS) Center, 2016).

\begin{tabular}{|c|c|c|c|}
\hline $\begin{array}{c}\text { Master } \\
\text { Image }\end{array}$ & $\begin{array}{c}\text { Slave } \\
\text { Image }\end{array}$ & $\begin{array}{c}\text { Perpendicular } \\
\text { Baseline }(\mathrm{m})\end{array}$ & $\begin{array}{c}\text { Temporal } \\
\text { Baseline(d) }\end{array}$ \\
\hline 20160808 & 20160816 & 483.1 & 8 \\
20160816 & 20160921 & 125.3 & 36 \\
20160921 & 20161007 & 118.8 & 16 \\
20161007 & 20161019 & -673.1 & 12 \\
20161019 & 20161222 & 101.7 & 64 \\
\hline
\end{tabular}

Table 1. COSMO-SkyMed image pairs

\section{TECHNICAL METHOD AND DATA PROCESSING}

The offset tracking technique can estimate offsets in slant-range and azimuth directions between two SAR images using a normalized cross correlation algorithm (Strozzi et al., 2002). The principle is to select a specific patch in the master image and match it with a search window in the slave image, then the cross-correlation coefficient of each position is calculated between two image patches. The cross-correlation maximum means matching is completed, and total offset is estimated (Gray et al., 1998).

In case of flat terrain in study area, a small perpendicular baseline available, and the effect of ionosphere can be ignored, the total offsets includes offset induced by glacier movement and offset caused by orbit residual error. (Deng et al., 2015). According to the second glacier inventory of China, the elevation of Shie glacier varies from $5193.3 \mathrm{~m}$ to $6934.6 \mathrm{~m}$. Therefore, topographic offset could not be ignored because of the rugged terrain. In this paper, we employed a DEM-assisted offset tracking technique to remove topographic effects. The core is creating a co-registration lookup table, which makes use of an external DEM of study area and orbit information and then establishes the mapping relations between two SAR images. Topographic offset is calculated into the lookup table, so we can obtain accurate offset results without orbit residual error (GAMMA Remote Sensing, 2014). The procedure is divided into three main steps. In the first step, an initial coregistration lookup table is generated. In this step a DEM in radar geometry of the reference SAR image is generated through geocoding. A mapping between DEM and reference SAR image is obtained and then establishes the mapping between slave SAR image and DEM. Combining two mapping relations, the initial co-registration lookup table is generated which contains topographic offset and systematic offset between two SAR images. The second step is the refinement of the initial co-registration lookup table. Resampling reference SAR image into the geometry of slave SAR image using the initial co-registration lookup table and further using the image cross-correlation method to obtain the offset polynomial which 
is used to refine the lookup table that can reduce the errors due to the inaccuracy of orbital data and DEM. In the third step, based on the new co-registration lookup table, resampling slave SAR image into the geometry of reference SAR image, then we can calculate the glacier offset fields in azimuth and slant-range directions which have removed the topographic and systematic offset using the technique.

In order to improve efficiency of data processing, we clipped the COSMO-SkyMed images suitably. And it was tested several times to search appropriate patch window size. It was found that when the window is too large, it could not save the details well. When the window is too small, the glacier movement distributes more randomly, which is hard to analyze. Best results were acquired when applied a patch window size of $100 * 100$ pixels in slant-range and azimuth directions.

\section{RESULTS AND ANALYSIS}

The velocity fields in slant-range and azimuth directions of Shie glacier based on COSMO-SkyMed images were successfully extracted. Assuming that the direction of movement is parallel to the surface of glaciers, a 3-D displacement map can be acquired using a high-resolution and high-precision DEM combined with the 2-D velocity field (Goldstein et al., 1993; Strozzi et al., 2008; Jiang et al., 2012). But the DEM in the study area would further bring the error because of its low resolution and precision in this paper. Therefore, assuming that the glacier surface is horizontal, synthesizing the ground-range and azimuth velocity fields to represent the glacier surface movement (Hamish et al., 2005). And then the displacement fields are geocoded into the geometry of SRTM. The final results for Shie glacier are shown in Figure 2.

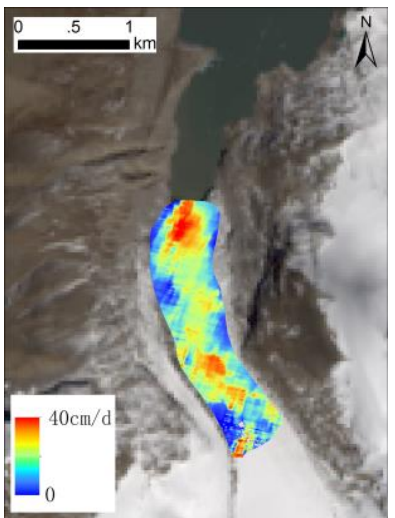

(a) 20160808-20160816

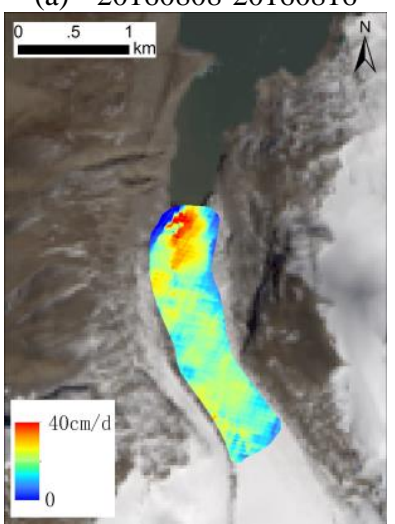

(c) 20160921-20161007
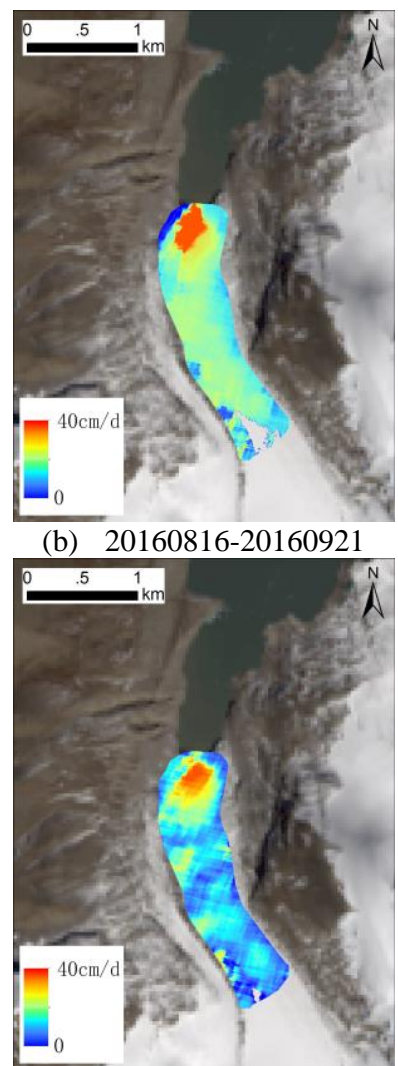

(d) 20161007-20161019

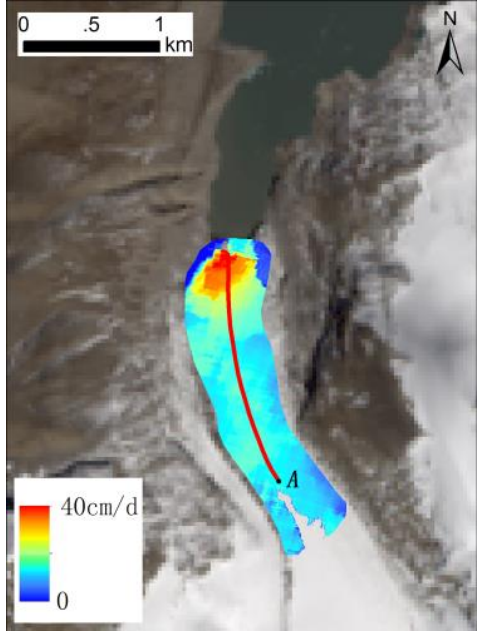

(e) 20161019-20161222

Figure 2. Velocity maps of Shie glacier

\subsection{Error analysis}

With a harsh environment and a steep terrain, it is difficult to measure the surface velocity of the glacier from field survey and there are not previous studies regarding the movement of Shie glacier. For that reason, the reliability of offset tracking technique could not be verified by comparing to field or former records. There is a hypothesis when we extract glacier surface movement using offset tracking technique, that is, the values in stable zones are zero between the time interval of two SAR images (Yan Shiyong, 2013). Therefore, the accuracy of offset tracking technique can be estimated using root mean square error (RMSE) of displacement in the stable zones. RMSEs of 5 pairs of offset-tracking results in non-glacier regions were calculated and summarized in Table 2.

\begin{tabular}{|c|c|c|}
\hline $\begin{array}{c}\text { Master image/Slave } \\
\text { image }\end{array}$ & $\begin{array}{c}\text { Temporal } \\
\text { Baseline(d) }\end{array}$ & RMSE (m) \\
\hline $20160808 / 20160816$ & 8 & 0.09 \\
$20160816 / 20160921$ & 36 & 0.13 \\
$20160816 / 20160921$ & 16 & 0.07 \\
$20160816 / 20160921$ & 12 & 0.17 \\
$20161019 / 20161222$ & 64 & 0.11 \\
\hline
\end{tabular}

Table 2. The RMSE in stable zones of Shie glacier

The RMSEs are $0.09,0.13,0.07,0.17$ and $0.11 \mathrm{~m}$ for 20160808 to 20160816,20160816 to 20160921,20160816 to 20160921 , 20160816 to 20160921,20161019 to 20161222 . Hence, the mean RMSEs are 1.1, 0.3, 0.4, 1.4 and $0.2 \mathrm{~cm} / \mathrm{d}$ which are much lower than the average daily velocities of Shie glacier, indicating that the accuracy of offset tracking technique is high and has a good reliability.

\subsection{Analysis of glacier surface velocity}

The velocity maps of Shie glacier have similar distributions during the five periods, which illustrates the reliability of the velocity fields of glacier to a certain degree. The maximum velocity of Shie glacier is distributed at the end of the glacier tongue. In order to analyze the relationship between the velocity and the change of elevation and time, the velocity profile along the axis of Shie glacier tongue is extracted (Figure 2(e)). The results are shown in Figure 3, where Distance 
represents the distance from the point on the profile to the initial point $\mathrm{A}$. The glacier surface velocities alone the profile have good consistency in five periods. At the up and middle of the glacier tongue, the velocities are mostly small and stable. And the glacier velocities begin to increase to the maximum at the end of glacier tongue. Compared with the changes of glacier elevation along the profile, the glacier terminus has also a dramatic change for elevation, where the increase in velocity is mainly due to the sudden increase in terrain slope. And the highest velocity is $51 \mathrm{~cm} / \mathrm{d}$.

The averages of five velocity profiles of the glacier surface velocity maps are $29 \mathrm{~cm} /$ day (20160808-20160816), $25 \mathrm{~cm} /$ day (20160816-20160921), 20cm/day (20160921-20161007), $17 \mathrm{~cm} /$ day (20161007-20161019) and $19 \mathrm{~cm} /$ day $(20161019-$ 20161222). According to the acquisition time of SAR images, the average of glacier surface velocity from August to September is higher than the average from October to December. From summer to winter, the flow velocity of Shie glacier is decreasing. And combined with the local temperature from August to December, it is approximately found that when the local temperature decreases, the velocity also decreases.

The velocity of the end of Shie glacier tongue is the fastest part of the whole glacier. Moreover, the glacier terminus has a steeper slope. With the constant movement of the glacier, the length of glacier floating on Sangwang lake would be increasing and eventually the glacier tongue may break off at the end of tongue in the not so distant future.

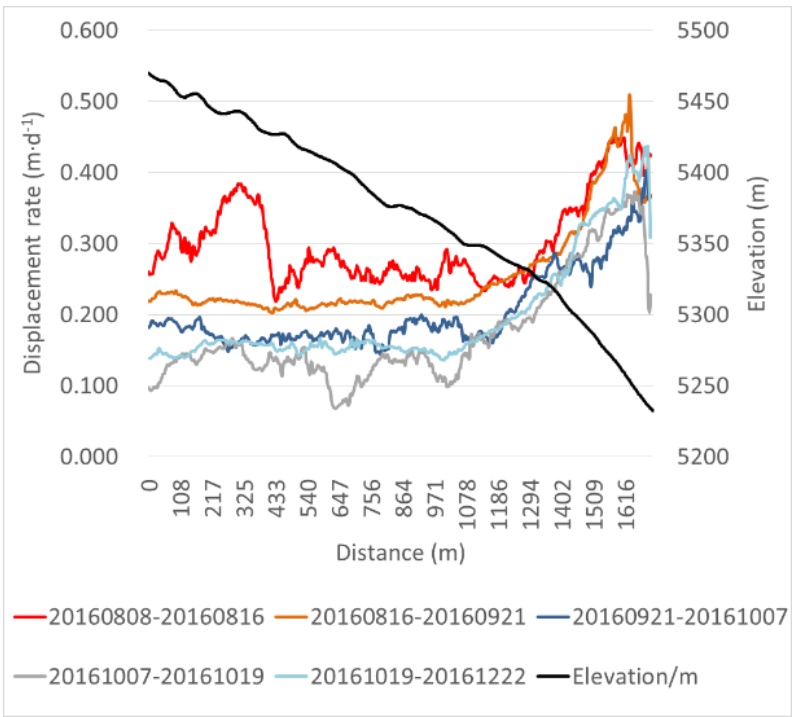

(a)

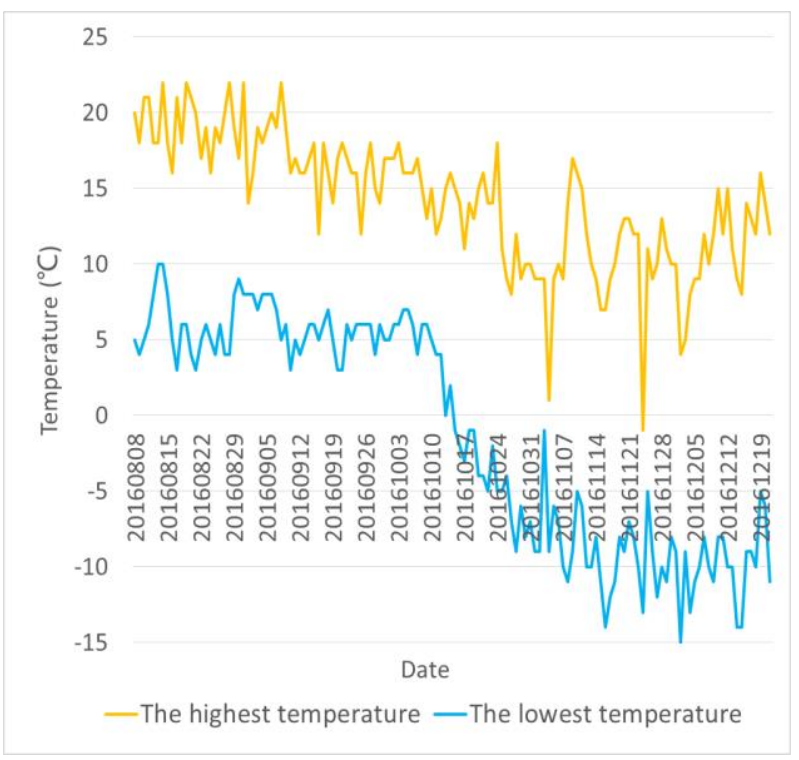

(b)

Figure 3. Shie glacier surface velocities alone the profile in different periods (a) and the change of local temperature from August to December (b).

\section{CONSLUSION}

Based on intensity information of SAR images, the offset tracking technique can directly obtain the displacement maps of glacier surface in both azimuth and slant-range directions whether the coherence retained or not, which is a useful technique in monitoring glacier surface movement. The launch of high-resolution SAR satellites provides more possibility for monitoring small glaciers and their surface movement better. In this paper, the 2-D surface movement of Shie glacier from August to December was estimated using 6 COSMO-SkyMed images with the DEM-assisted offset tracking technique which can remove the offset caused by topography. The spatial consistency of glacier velocity distributions and the lower RMSEs in non-glacier zones verify the reliability of this technique. The results show that the maximum velocity $51 \mathrm{~cm} /$ day is at the end of Shie glacier tongue where elevation has also a dramatic change and the glacier movement is related to local temperature. The velocity decreases as the local temperature decreases. And a collapse may occur at the end of glacier tongue due to the fast velocity and steep slope.

\section{ACKNOWLEDGEMENTS}

This work was supported by China Geological Survey (Project No. DD20160342) and the Dragon 4 Programme (Project No. 32365).

\section{REFERENCES}

Casu, F., Manconi, A., Pepe, A., \& Lanari, R., 2011. Deformation time-series generation in areas characterized by large displacement dynamics: the SAR amplitude pixel-offset SBAS technique. IEEE Transactions on Geoscience \& Remote Sensing, 49(7), 2752-2763.

Deng, F.H., ZHOU, C.X., WANG, Z.M., E, D.C., Zhang, X., 2015. Ice-flow Velocity Derivation of the Confluence Zone of the Amery Ice Shelf Using Offset-tracking Method. Geomatics and Information Science of Wuhan University, 40(7): 901-906. 
Fallourd, R., Harant, O., Trouvé, E., Nicolas, J. M., Gay, M., Walpersdorf, A., \& Vasile, G., 2011. Monitoring temperate glacier displacement by multi-temporal TerraSAR-X images and continuous GPS measurements. IEEE Journal of Selected Topics in Applied Earth Observations and Remote Sensing, 4(2), 372-386.

GAMMA Remote Sensing., 2014. Differential Interferometry and Geocoding Software-DIFF\&GEO (Geocoding and Image Registration). Switzerland: GAMMA Remote Sensing AG.

Goldstein, R. M., Engelhardt, H., Kamb, B., \& Frolich, R. M., 1993. Satellite radar interferometry for monitoring ice sheet motion: application to an Antarctic ice stream. Science, 262(5139), 1525-1530.

Gray, A. L., Mattar, K. E., Vachon, P. W., \& Bindschadler, R., 1998. InSAR results from the RADARSAT Antarctic Mapping Mission data: estimation of glacier motion using a simple registration procedure. Geoscience and Remote Sensing Symposium Proceedings, 1998. IGARSS '98. 1998 IEEE International (Vol.3, pp.1638-1640 vol.3). IEEE.

Hamish, P., Tavi, M., Adrian, L., Tazio, S., \& Stuart, B., 2005. Glacier surge dynamics of Sortebræ, east Greenland, from synthetic aperture radar feature tracking. Journal of Geophysical Research Atmospheres, 110(F3).

Italian Space Agency., 2016. COSMO-SkyMed Mission and Products Description http://www.e-geos.it/cosmo-skymed.html.

Jiang, Z. L., Liu, S. Y., Peters, J., Lin, J., Long, S. C., \& Han, Y S., et al., 2012. Analyzing Yengisogat glacier surface velocities with ALOS PALSAR data feature tracking, Karakoram, China. Environmental Earth Sciences, 67(4), 1033-1043.

Li, J., Li, Z., Zhu, J., Ding, X., Wang, C., \& Chen, J., 2013. Deriving surface motion of mountain glaciers in the Tuomuerkhan Tengri mountain ranges from PALSAR images. Global \& Planetary Change, 101, 61-71.

Lin, H., Ke, C.Q., 2016. Monitoring Surface Deformation in Changzhou City Using COSMO-SkyMed Data. Remote Sensing Technology and Application, (3), 599-606.

Liu, C.L., Tong, L.Q., Qi, S.W., Zhang, S.S., Zheng, B.W., 2016. Remote sensing investigation and influence factor analysis of glacier lake outburst potential in the Himalayas. REMOTE SENSING FOR LAND \& RESOURCES, 28(3): 110115 .

Kääb, A., 2005. Combination of srtm3 and repeat aster data for deriving alpine glacier flow velocities in the Bhutan Himalaya. Remote Sensing of Environment, 94(4), 463-474.

Kääb, A., 2005. Remote sensing of mountain glaciers and permafrost creep (Vol. 48). Geograph. Inst. d. Univ.

Parry, M. L., Canziani, O. F., Palutikof, J. P., Linden, P. J. V. D., \& Hanson, C. E., 2007. Contribution of working group ii to the fourth assessment report of the intergovernmental panel on climate change. Encyclopedia of Language \& Linguistics, 12(1), 171-175.

Ran, Q.H., Wu, X.S., He, Z.G., Qian, Q., Wang, F., Yu, X., 2014. Influence of glacier lake outburst mode on downstream flood process. Journal of Tsinghua University (Science and Technology, (8), 1049-1056.

Riveros, N., Euillades, L., Euillades, P., Moreiras, S., \& Balbarani, S., 2013. Offset tracking procedure applied to high resolution SAR data on Viedma Glacier, Patagonian Andes, Argentina. Advances in Geosciences, 35, 7-13.

Strozzi, T., Luckman, A., Murray, T., \& Wegmuller, U., 2002. Glacier motion estimation using SAR offset-tracking procedures. Geoscience \& Remote Sensing IEEE Transactions on, 40(11), 2384-2391.

Strozzi, T., Kouraev, A., Wiesmann, A., Wegmüller, U., Sharov, A., \& Werner, C., 2008. Estimation of Arctic glacier motion with satellite L-band SAR data. Remote Sensing of Environment, 112(3), 636-645.

USGS Earth Resource Observation and Science (EROS) Center., 2016. Global Data Explorer (GDEx) Data Access User Guide https://gdex.cr.usgs.gov/gdex/.

Wang, S.S., Jiang, L.M., Sun, Y. L., Liu, L., Sun, Y.F., Wang, H.S., 2016. Evaluation of methods for deriving mountain glacier velocities with ALOS PALSAR images: A case study of Skyang glacier in central Karakoram. REMOTE SENSING FOR LAND \& RESOURCES, 28(2): 54-61.

Yan, S.Y., 2013. Research on extraction of Alpine glacier surface movement by SAR remote sensing. The Institute of Remote Sensing and Digital Earth, Chinese Academy of Sciences, pp.49-68.

Zhou, C.X., Deng, F.H., Chen, Y.M., Wang, Z.M., 2015. Iceflow Features in the Grove Mountains Area Using SAR Data. GEOMATICS AND INFORMATION SCIENCE OF WUHAN UNIVERS, 40(11): 1428-1433. 